\title{
Characterization of Psychoactive, Addictive, and Neurotoxic Effects of New Synthetic Amphetamine-like 2C-B, 2C-I and PMMA in Mice
}

\author{
Chen Chang-Mu ${ }^{1,+}$, Wu Cheng-Tien², Lin Jen-Kun ${ }^{4}$, Liu Shing-Hww ${ }^{1,2}$, Lin-Shiau Shoei-Yn ${ }^{3,+}$
}

\begin{abstract}
Rationale:

The traditional illicit drugs such as cocaine, marijuana, and methamphetamine (MA) have had the attention of general public. Designer drugs were created in the 1960s by preparing analogs or derivatives of currently available drugs to avoid legal restrictions. MA is a psychostimulating drug with significant abuse potential and neurotoxic effects. 4-bromo-2,5dimethoxyphenethylamine (2C-B), 4-iodo-2,5-dimethoxyphenethylamine $(2 \mathrm{C}-\mathrm{I})$, and paramethoxy-methamphetamine (PMMA) are all phenylethylamine derivatives that are popular new synthetic psychoactive phenylethylamines. There is a substantial lack of evidence about their psychostimulating, addictive, and neurotoxic effects in the scientific literature.
\end{abstract}

\section{Objectives:}

In this study, we performed behavioral tests to explore the psychoactive, addictive, and neurotoxic effects induced in mice after drug treatments.

\section{Methods:}

Mice were treated with intraperitoneal (i.p.) injections of saline, MA, 2C-B, 2C-I, and PMMA for 4 consecutive days. After no injections for one week, another 4 days of injections were repeated.

\section{Results:}

The behavioral tests showed impaired locomotion performance, rotarod balance performance, and water maze tests, increased conditioned preference place (CPP), and decreased time spent in the open field in the plus maze after injection. Neurochemical studies showed abnormal NOx, LPO, and $\mathrm{Na}^{+}, \mathrm{K}^{+}$-ATPase activities in brain tissues after injection. Body weight decrease and gross appearances like untidy fur, back hump, and awkward stance were also noted in mice receiving injections. Our results demonstrated that injections of $M A, 2 C-I, 2 C-B$ and PMMA in mice can impair motor activities, balance and memory performance, induce addiction and depression, and cause neurochemical abnormalities in brain tissues.

\section{Conclusion:}

In studies of the psychoactive, addictive, and neurotoxic effects of MA, 2C-I, 2C-B and PMMA in

'Department of Surgery, National Taiwan University Hospital and National Taiwan University College of Medicine, Taipei, Taiwan

${ }^{2}$ Institute of Toxicology, College of Medicine, National Taiwan University, Taipei, Taiwan

${ }^{3}$ Institute of Pharmacology, College of Medicine, National Taiwan University, Taipei, Taiwan

${ }^{4}$ Institute of Biochemistry, College of Medicine, National Taiwan University, Taipei, Taiwan

${ }^{\dagger}$ Author for correspondence: Chang-Mu Chen, Department of Surgery, National Taiwan University Hospital and National Taiwan University College of Medicine, Taipei, Taiwan, \#7, Section 1, Chung-Shan S. Rd., Taipei, Taiwan. Tel: +886 (2) 2312-3456, ext: 65324, Fax: +886 (2) 2312-3456, ext: 63110; email: cmchen10@ms27.hinet.net

Lin-Shiau Shoei-Yn, Institute of Pharmacology, College of Medicine, National Taiwan University, \#1, Section 1, Jen-Ai Road, Taipei, Taiwan. Tel: +886 (2) 2312-3456, ext: 88313, Fax: +886 (2) 2391-5297; email: syshiau@ntu.edu.tw 
mice, we found that these designer drugs had fewer psychostimulating effects than MA, but comparable addictive and neurotoxic effects. Based on our results, proper legal restriction of and information campaigns against these designer drugs are warranted to control drug abuse and counter the adverse effects of these drugs.

\section{Keywords}

MA, 2C-I, 2C-B, PMMA, Psychostimulation, Addiction, Neurotoxicity

\section{Introduction}

The traditional illicit drugs such as cocaine, marijuana, and methamphetamine (MA) have had the attention of the general public and the authorities. However, designer drugs were created in the 1960 s by preparing analogs or derivatives of currently available drugs to avoid legal restrictions [1]. In order to stay ahead of the drug laws, manufacturers of designer drugs purposely changed the structure of these drugs, making it difficult for clinicians to discern. Structural manipulation to produce new compounds, advertisement of these compounds as "legal" highs, and ease of access to designer drugs on the internet, at raves and night clubs, and on sale in head shops have rejuvenated and promoted the current designer drug resurgence [2].

MA is a psychostimulating drug with significant abuse potential and neurotoxic effects. Its principal mechanism of action is to cause the release of central and peripheral monoamines and their subsequent effects [3]. In 1971, MA was restricted by US law, but oral MA continues to be used today clinically as a second-line treatment for a number of medical conditions, including attention deficit hyperactivity disorder (ADHD) and refractory obesity [4]. The 2008 United Nations Office on Drugs and Crime (UNODC) world drug report estimated that there were approximately 25 million abusers of MA worldwide, exceeding that for cocaine (14 million) and heroin (11 million) [5]. The 2011 UNODC report describes the MA problem as a global epidemic, citing an unprecedented rise in use compared to other illicit substances [6].

Many new synthetic psychoactive phenylethylamines have spread through the illicit market around the world during the last 2 decades. Among these drugs, 4-bromo-2,5dimethoxyphenethylamine (2C-B), 4-iodo-2,5dimethoxyphenethylamine (2C-I), and paramethoxy-methamphetamine (PMMA) are all phenylethylamine derivatives that are popular in their use (Dean et al. 2013). In spite of their popularity among recreational drug users, there is a substantial lack of evidence about their psychostimulating, addictive, and neurotoxic effects in the scientific literature. There have been reports recently of drug intoxication after using these designer drugs, and side effects including seizure, psychosis, and even death [7-9]. Therefore, a detailed animal study to characterize the neurobehavioral and neurotoxic effects of these drugs is needed for guidance and regulation of their use. In this study, we performed behavioural tests to explore the psychoactive, addictive, and neurotoxic effects of these drugs in mice. The neurochemical profiles in different parts of the brain of mice were also examined to determine the underlying pathophysiology after drug injection.

\section{Materials and Methods \\ - Mice}

The experiment protocols were approved by the Hospital Animal Research Committee of National Taiwan University Hospital. Adult male ICR mice, aged 4-5 weeks and weighing $18-25 \mathrm{~g}$, were used in this study. Mice were housed under air-conditioned and illuminated conditions to maintain the temperature at $22 \pm$ $1.5^{\circ} \mathrm{C}$, humidity at $40-60 \%$, and a $12-12$-hour dark-light cycle.

\section{- Treatment of the mice}

In order to elicit behavioural sensitization, mice received intraperitoneal injections of drugs (saline, 2C-I, 2C-B, PMMA) for 4 consecutive days $(10 \mathrm{mg} / \mathrm{kg} /$ day $)$, and after one week without an injection, the mice were given another 4 days of injections $(20 \mathrm{mg} / \mathrm{kg} / \mathrm{day})$. There are 5 groups that receiving different kinds of drug injection. Each group consisted of 6 mice.

\section{- Locomotor activity test}

Locomotor activities of the mice were assessed with TruScan photobeam tracking as previously described [10]. In brief, 10 minutes after injection, the mice were put in a tracking device. 
The first 5 minutes were used for adaptation, and then continuous tracking for 1 hour. The results were recorded every 10 minutes.

\section{- Motor equilibrium performance on the rotarod}

The mice were tested for their ability to balance on a slowly rotating rod (60 revolutions per $\mathrm{min}$ ) as described previously [11]. One day before the experiment, the ability of the mice to stay on the rod and reach the cut-off time of $180 \mathrm{~s}$ for 10 consecutive sessions was tested. One day after injection, the mice were tested again. The retention time, defined as the total time $(\mathrm{sec})$ remaining on the rod, was recorded for each session.

\section{- Conditioned preference place (CPP)}

The CPP tests were performed as described by Itzhak and Martin with some modifications [12]. In the preconditioning test, the mice were allowed to move freely between 2 chambers with the sliding door opened for 15 minutes per day. The tests were continued for 3 days. In the conditioning test, the mice were injected with 2C-I, 2C-B or PMMA, and put in a dark chamber with the sliding door closed for 40 minutes. The next day, mice were injected with saline and put in a stripe chamber with the sliding door closed for 40 minutes. The same process was repeated 3 times for a total of 6 days. In the post-conditioning test, the mice were put in chambers with the sliding door opened, and the time the mice spent in the dark or stripe chambers was recorded.

\section{- Elevated plus maze}

The apparatus consisted of a wooden, plus shaped maze, elevated $60 \mathrm{~cm}$ above ground and comprised of two dark, enclosed arms with 24 $\mathrm{cm}$ walls, and two lit, open arms with a $1 \mathrm{~cm}$ lip. The size of each arm was $30 \mathrm{~cm} \times 5 \mathrm{~cm}$ with a $5 \mathrm{~cm} \times 5 \mathrm{~cm}$ center area. Each mouse was individually placed in the center of the maze and its behavior digitally recorded from above for a 5 min session. Recordings served to manually score the time spent in the open and the closed arms and the number of entries to each arm. Time in the open arms, in the closed arms, number of entries to the open arms or the closed arms and the ratio of open arms/closed arms time served for statistical analysis.

\section{- Morris water maze}

The water maze consisted of a featureless circular pool (diameter: $2.0 \mathrm{~m}, 60 \mathrm{~cm}$ high) that was filled with water and $2 \mathrm{~L}$ milk to a depth of 30 $\mathrm{cm}$. A hidden black escape platform (diameter: $21 \mathrm{~cm}$ ) was placed in one of its quadrants such that its top lay $1 \mathrm{~cm}$ beneath the water surface. Each trial was initiated by placing the mice in one of the 3 other quadrants near the wall of the pool. The mice were allowed to search for the escape platform for a maximum of $90 \mathrm{~s}$. Those that failed to locate the platform within this period were guided to it by the experimenter. The mice remained on the platform for $15 \mathrm{~s}$ prior to removal from the maze. They were trained 4 times per day for 9 days. The average time needed to find the escape platform could be shortened through learning and memory and represented memory consolidation. After 9 days, the escape platform was removed, and the mice were put in the pool for $90 \mathrm{~s}$. The time that target quadrant mice stayed represented memory retention.

\section{- Lipid peroxidation (LPO) of brain tissue}

The measurement of LPO in brain tissue was conducted using the method described by Kim, et al. with some modifications [13]. The mice were anesthetized with pentobarbital (50 $\mathrm{mg} / \mathrm{kg}$ ), and then sacrificed by decapitation. The brain tissue was dissected and stored at $-70^{\circ} \mathrm{C}$. Then, $100 \mathrm{mg}$ of brain tissue (cerebral cortex, cerebellum, brainstem, and striatum) was harvested and homogenized in $20 \mathrm{mM}$ Tris- $\mathrm{HCl}$ buffer, $\mathrm{pH} 7.4$, containing $0.5 \mathrm{mM}$ butylated hydroxytoluene to prevent sample oxidation. After centrifugation, 3.25 volumes of diluted R1 reagent (10.3 mM N-methyl-2phenylindole in acetonitrile) were added to the supernatant, followed by gentle vortex mixing. After addition of 0.75 volumes of $37 \% \mathrm{HCl}$, the mixtures were incubated at $45^{\circ} \mathrm{C}$ for $60 \mathrm{~min}$. After cooling and centrifugation, the absorbance of the clear supernatant was read at $590 \mathrm{~nm}$. The protein concentration was determined using the bicinchoninic acid protein assay kit (Pierce, Rockford, IL).

\section{- Nitric oxide (NO) in brain tissue}

Next, $100 \mathrm{mg}$ of brain tissue (cerebral cortex, cerebellum, brainstem, and striatum) was harvested and homogenized in 10\% (w:v) homogenate buffer (10\% sucrose buffer), and then centrifuged at $0^{\circ} \mathrm{C}$ for $20 \mathrm{~min}$ at 10000 $\times g$. To avoid incomplete protein denaturation, we added $70 \%$ ethanol to the tissue pellet, and allowed the mix to stand overnight. On the following day, all samples were centrifuged at $4^{\circ} \mathrm{C}$ for $20 \mathrm{~min}$ at $12000 \times \mathrm{g}$, and the supernatants from the brain tissue were collected and assayed 
by a NO:ozone chemiluminescence assay method (NO-Analyzer 280A, Sievers Research Inc., Boulder, CO, USA) for quantitative NO assay, as described previously [10].

\section{- Measurements of $\mathrm{Na}^{+}, \mathrm{K}^{+}-$ATPase activity}

ATPase activities were determined by measuring the amount of inorganic phosphate (Pi) released from the substrate ATP, according to a previously described colorimetric method [14]. In brief, ATPase reactions were initiated in a mixture containing $\mathrm{NaCl}(354 \mathrm{mM}), \mathrm{KCl}(14.4$ $\mathrm{mM}), \mathrm{MgCl}_{2}(3.6 \mathrm{mM}), \mathrm{NaHCO}_{3}(37.5 \mathrm{mM})$, ethyleneglycol bis(amino-ethylether) tetraacetate (EGTA, $1.5 \mathrm{mM})$, glucose $(33.3 \mathrm{mM})$ and ATP $(9 \mathrm{mM})$, and in the absence or presence of ouabain $(1 \mathrm{mM})$. Brain tissues from different brain areas were incubated at $37 \pm 0.5^{\circ} \mathrm{C}$ for 30 $\min$ in the reaction mixture. Reactions were terminated by the addition of $150 \mu$ l of a solution containing ammonium molybdate (1.05\%), malachite green hydrochloride $(0.034 \%)$ and Triton-X $(0.6 \%)$. To stabilize the color reaction, $10 \mu \mathrm{l}$ of a sodium citrate solution (34\%) was added, and the assay solution was held at room temperature for $20 \mathrm{~min}$. The optical density at $630 \mathrm{~nm}$ was determined by an ELISA reader (Dynatech MR-7000). The absorbance values obtained were converted to activity values by linear regression using a standard curve for sodium monobasic phosphate included in the assay at various concentrations. Pi released (in $\mathrm{mmol} / \mathrm{l}$ ) was taken to represent the concentration of inorganic phosphate released by the enzymatic hydrolysis of ATP. $\mathrm{Na}^{+}, \mathrm{K}^{+}$-specific ATPase activity was determined by subtracting ouabaininsensitive $\mathrm{Mg}^{2+}$-ATPase activity from total $\mathrm{Na}^{+}, \mathrm{K}^{+}$- and $\mathrm{Mg}^{2+}$-ATPase activities. Protein concentration was determined colorimetrically with a commercial bicinchoninic acid kit (Pierce, Rockford, IL).

\section{Statistical analysis}

Statistical comparisons between study groups were performed using the ANOVA test followed by Dunnett's test. $P$ values of less than 0.05 were considered to be biologically significant.

\section{Results}

In order to elicit behavioral sensitization, mice received intraperitoneal injections of drugs (saline, 2C-I, 2C-B, PMMA) for 4 consecutive days $(10 \mathrm{mg} / \mathrm{kg} / \mathrm{day})$, and after one week without an injection, the mice were given another 4 days of injections $(20 \mathrm{mg} / \mathrm{kg} / \mathrm{day})$. Under this dosage, mice showed decreased body weight, untidy fur, back hump, and awkward stance after injection.

\section{- Locomotor activities}

With injection of 2C-I, the mice showed decreased ambulation distance in the first 4 days (first phase), which persisted through the last 4 days (second phase). Injection with 2C-B showed slightly decreased ambulation distance in the first phase, but significantly increased ambulation distance in the second phase. For PMMA, the ambulation distance increased in the first phase, but significantly decreased in the second phase (Figure 1A).

In contrast, rest time increased after injection of 2C-I and 2C-B, but decreased after PMMA injection in the first phase. During the second phase, rest time increased after 2C-I and PMMA injection, but decreased after 2C-B injection (Figure 1B).

Injection of 2C-I and 2C-B significantly decreased jumping activities, but the decrease was less significant after PMMA injection in the first phase. In the second phase, injection of 2C-I and PMMA significantly decreased, but 2C-B injection significantly increased jumping activities ((Figure 1C).

Injection of 2C-I, 2C-B and PMMA significantly decreased stereotype episodes in both the first and second phase. The decrease in stereotype episodes was most evident after 2C-B injection (Figure 1D).

Injection of 2C-I and 2C-B significantly decreased vertical plane entries, but the decrease was less significant after PMMA injection in the first phase. In the second phase, injection with 2C-I and PMMA significantly decreased, but 2C-B injection significantly increased vertical plane entries (Figure 1E).

In brief, the psychostimulating effects of PMMA were evident in the first phase, but decreased in the second phase. With 2C-I, no psychostimulating, and even negative psychostimulating effects were noted during the first and second phase. With 2C-B, initial negative psychostimulating effects were noted in the first phase, but pronounced psychostimulating effects were noted in the second phase.

In addition, the mice received methamphetamine (MA, $0.75 \mathrm{mg} / \mathrm{kg}$ ) intra-peritoneal injection, and the locomotor activities were comparable to those 
Characterization of Psychoactive, Addictive, and Neurotoxic Effects of New Synthetic Amphetamine-like Research 2C-B, 2C-I and PMMA in Mice
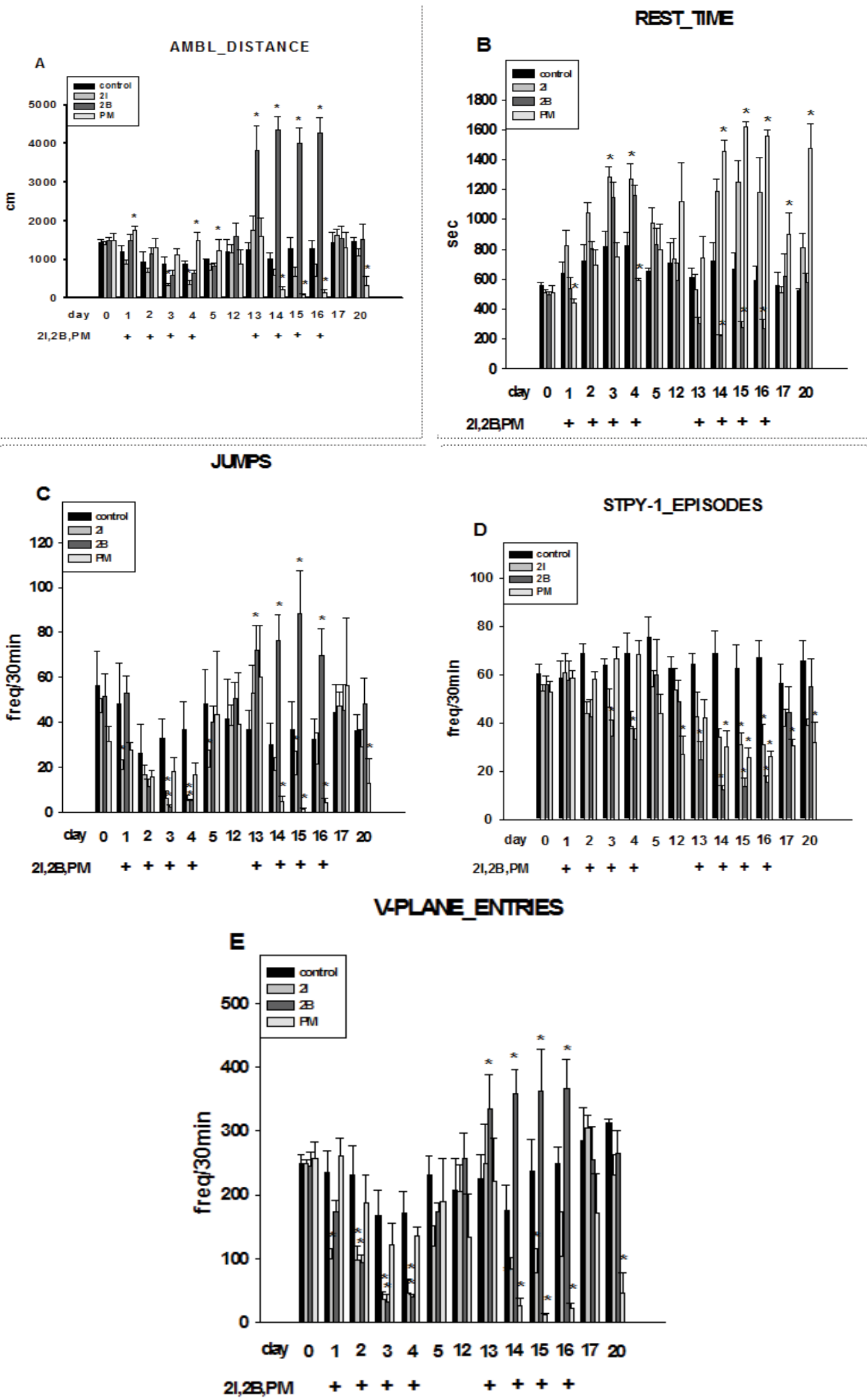

Figure 1: Locomotor activities of the mice after intra-peritoneal injection of saline, 2C-I, 2C-B and PMMA. (A) ambulation distance (B) rest time (C) jumps (D) stereotype- 1 episodes, and $(E)$ vertical plane entries. $\left({ }^{*} p<0.05\right)$. 
rotarod $60 \mathrm{rpm}$ score

A

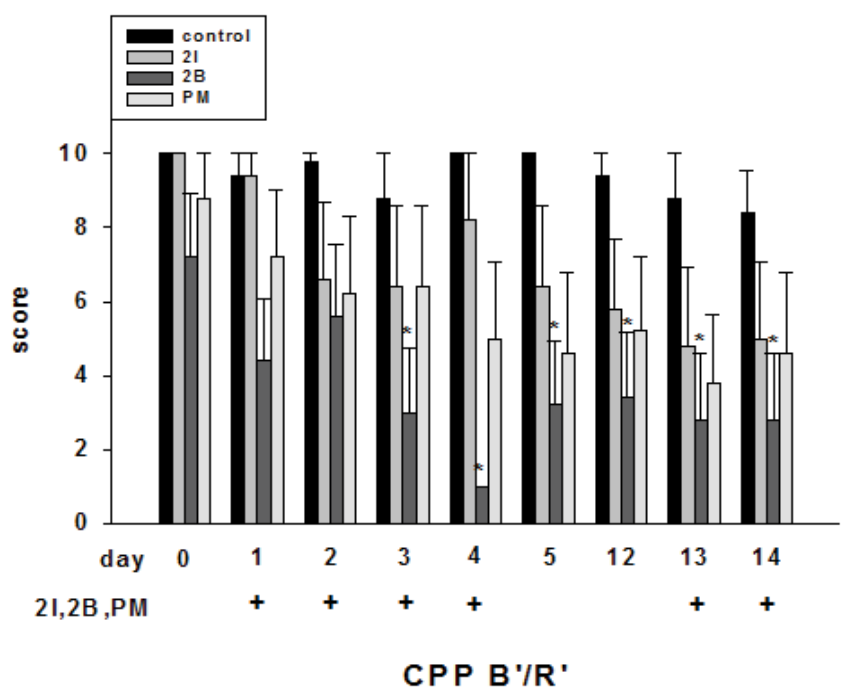

B

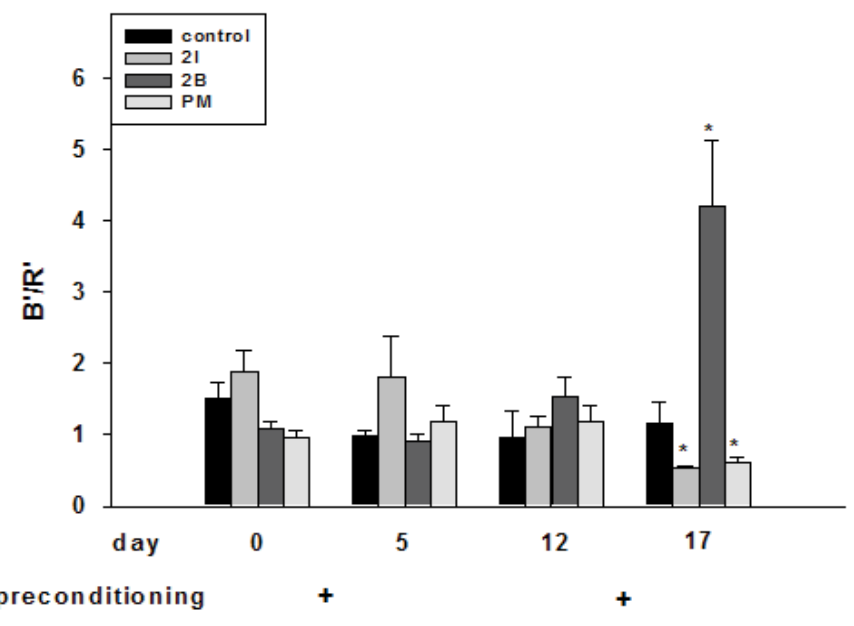

Figure 2: Rotarod performance (A) and conditioned preference place (CPP) (B) of the mice after intra-peritoneal injection of saline, 2C-I, 2C-B and PMMA. $\left({ }^{*} p<0.05\right)$.

of mice injected with 2C-I, 2C-B, and PMMA $(10 \mathrm{mg} / \mathrm{kg})$. Therefore, the psychostimulating potency of MA was at least 10 times that of $2 \mathrm{C}$ I, 2C-B, and PMMA.

\section{- Rotarod}

Injection of 2C-I, 2C-B and PMMA all significantly impaired rotarod performance in both the first and second phase. The impairment was most evident after 2C-B injection (Figure 2A).

\section{- Conditioned preference place (CPP)}

We performed CPP to test the addictive activity of the mice. In the first phase, injection of 2C-I slightly increased CPP. In the second phase, injection of 2C-B significantly increased
CPP. However, injection of 2C-I and PMMA decreased CPP (Figure 2B). The CPP results showed $2 \mathrm{C}-\mathrm{B}$ is far more addictive than $2 \mathrm{C}-\mathrm{I}$ and PMMA, and the reward effects of 2C-I and PMMA were not evident after repeated injections.

\section{- Plus maze}

In the plus maze, the mice showed no significant difference in time spent at the open field, closed field, and center before injection (Figure 3A). After injection of 2C-I and PMMA, the mice showed a significantly shorter time in the open field than the control group. Mice injected with 2C-B showed an insignificantly shorter time in the open field (Figure 3B).

\section{- Water maze}

The mice showed no significant difference in water maze performance before injection. However, injection with PMMA in the first phase, and injection of 2C-B and PMMA in the second phase both significantly impaired their performance in the water maze (Figure 4).

\section{- NOx of brain tissues}

Injection of 2C-I did not affect the production of $\mathrm{NOx}$ in brain tissues. Injection of 2C-B decreased the production of NOx in the cerebral cortex (Figure 5A \& 5B), but significantly increased the production of $\mathrm{NOx}$ in the brain stem and striatum (Figure 5C \& 5D). Injection of PMMA significantly increased the production of $\mathrm{NOx}$ in the brain stem and striatum (Figure 5C \& 5D).

\section{- LPO in brain tissues}

Injection of 2C-I significantly increased the production of LPO in the cerebellum and striatum. Injection of $2 \mathrm{C}-\mathrm{B}$ increased the production of LPO in the cerebral cortex and cerebellum, but significantly decreased its production in the striatum (Figure 6).

\section{- $\mathrm{Na}^{+}, \mathrm{K}^{+}$-ATPase activity in brain tissues}

Injection of 2C-I, 2C-B and PMMA did not affect the $\mathrm{Na}^{+}, \mathrm{K}^{+}$-ATPase activity in the cerebral cortex of the mice (Figure 7A). Injection of PMMA caused $\mathrm{Na}^{+}, \mathrm{K}^{+}$-ATPase activity to increase significantly in the cerebellum (Figure 7B), and injection of 2C-I significantly increased $\mathrm{Na}^{+}, \mathrm{K}^{+}-$ ATPase activity in the brain stem (Figure 7C). Injection of 2C-I, 2C-B and PMMA caused $\mathrm{Na}^{+}, \mathrm{K}^{+}$-ATPase activity to decrease significantly in the striatum (Figure 7D). 
Characterization of Psychoactive, Addictive, and Neurotoxic Effects of New Synthetic Amphetamine-like Research 2C-B, 2C-I and PMMA in Mice

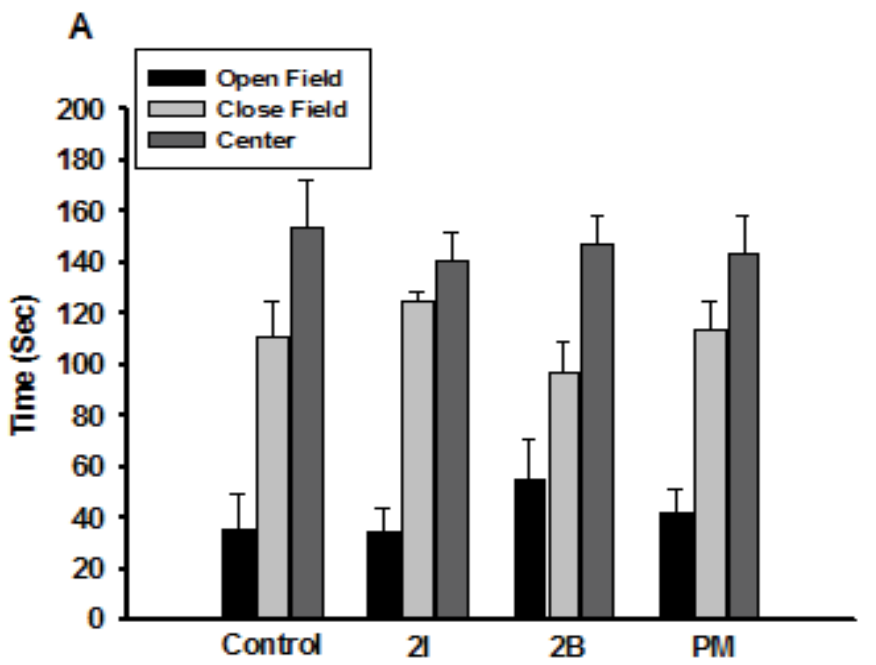

B

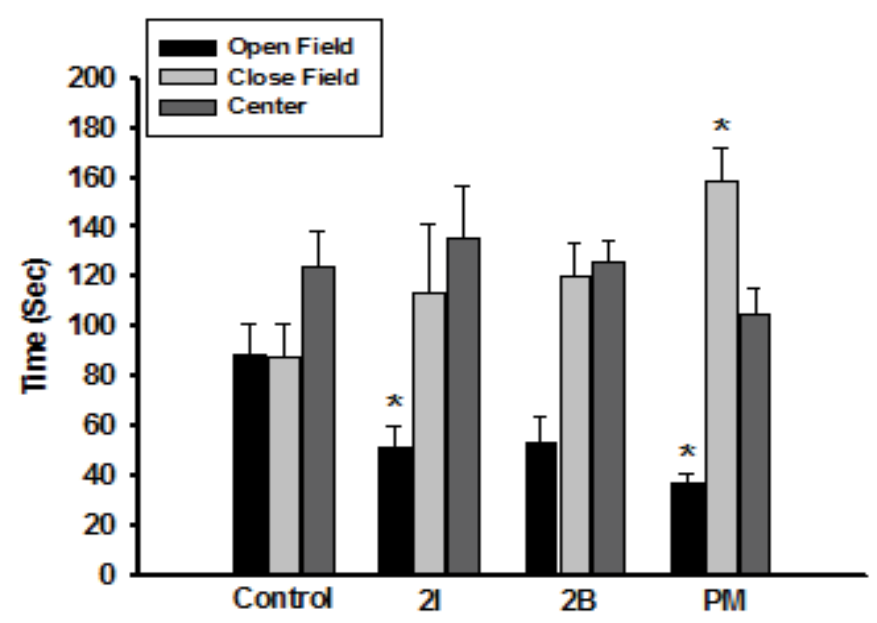

Figure 3: Plus maze test of the mice before (A), and after intra-peritoneal injection of saline, 2C-I, 2C-B and PMMA (B). ( $\left.{ }^{*} \mathrm{p}<0.05\right)$.

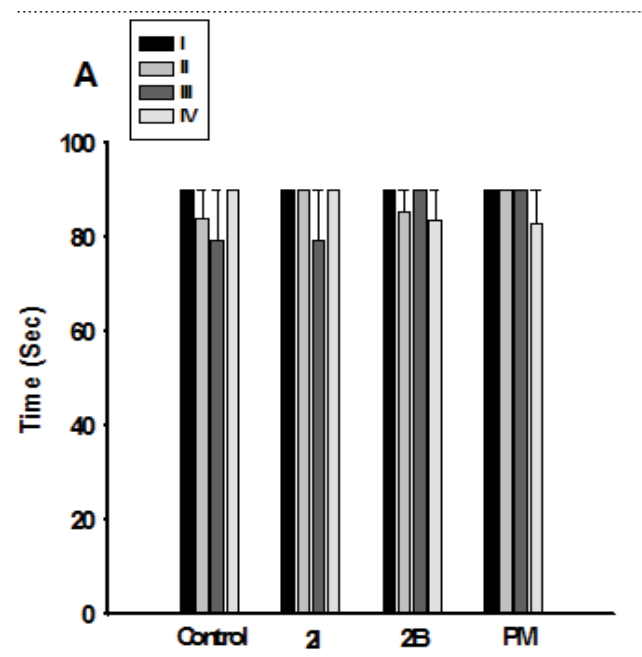

B

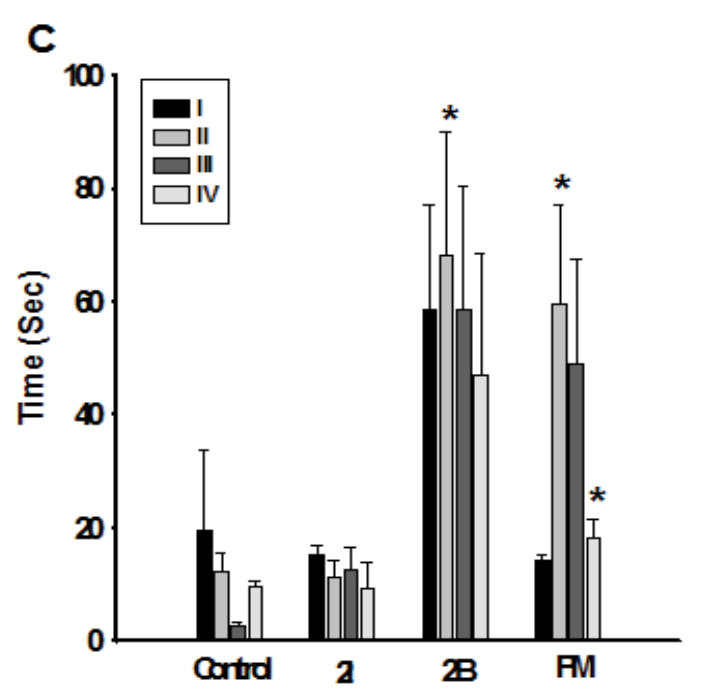

Figure 4: Water maze test of the mice before (A), 10 days (B), and 18 days $(C)$ after intra-peritoneal injection of saline, $2 C-1,2 C-B$ and $P M M A .\left({ }^{*} p<0.05\right)$. 
Research Lin-Shiau Shoei-Yn
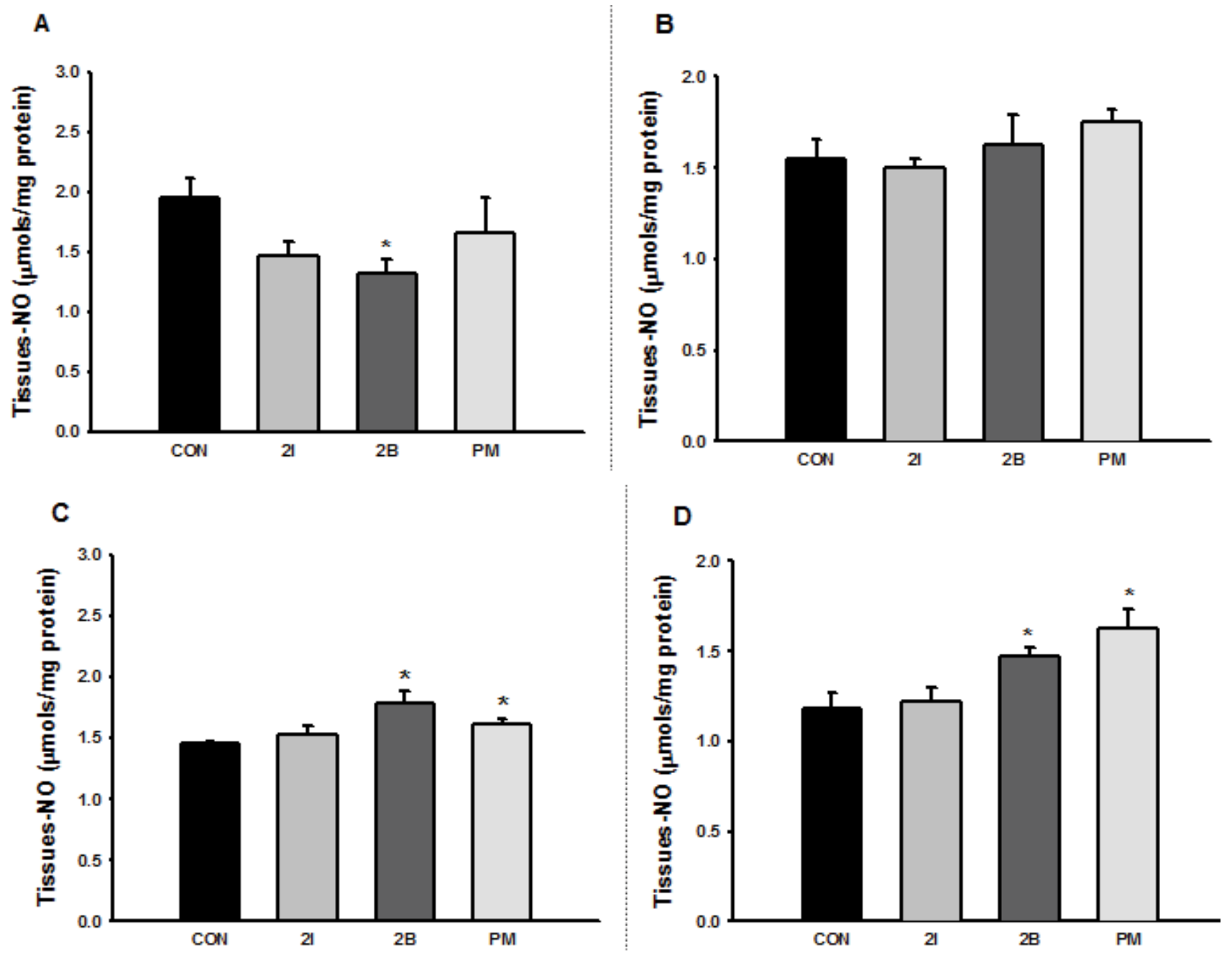

Figure 5: NOx in brain tissues. (A) Cerebral cortex; (B) Cerebellum; (C) Brain stem (C); and (D) Striatum (D). $\left.{ }^{*} p<0.05\right)$.

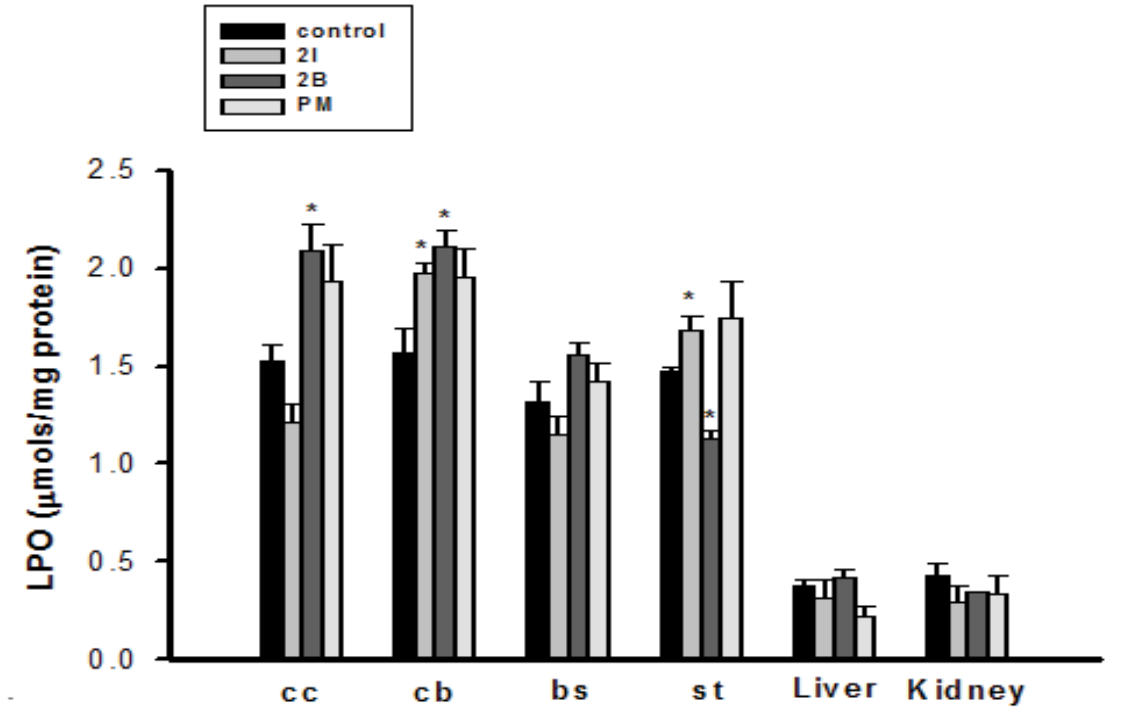

Figure 6: Lipid peroxidation (LPO) in brain tissues. (cc: cerebral cortex; cb: cerebellum; bs: brain stem; st: striatum) $\left({ }^{*} p<0.05\right)$. 
Characterization of Psychoactive, Addictive, and Neurotoxic Effects of New Synthetic Amphetamine-like Research 2C-B, 2C-I and PMMA in Mice

A

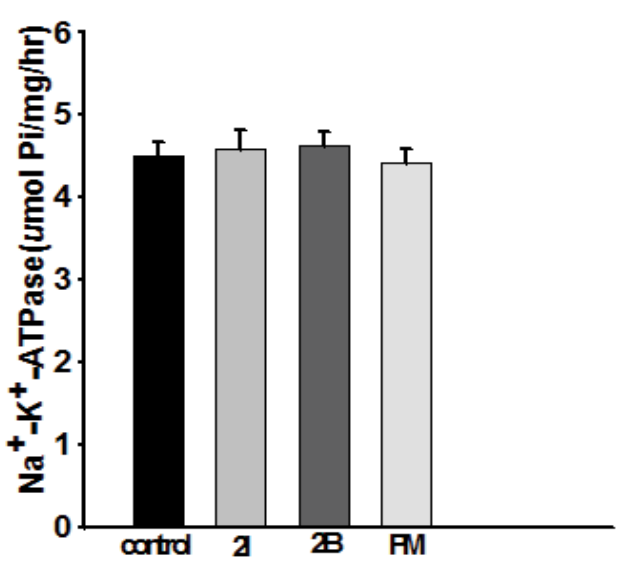

C

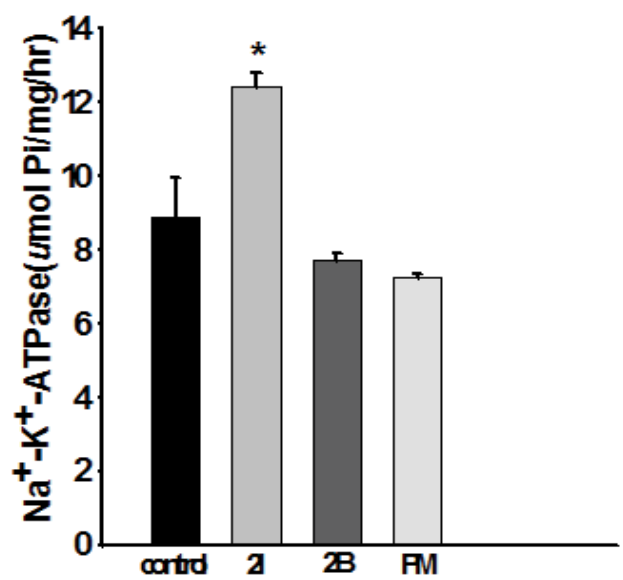

B

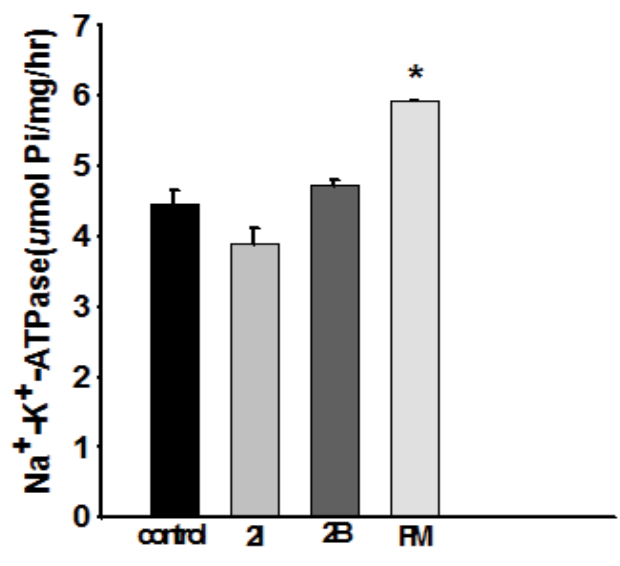

D

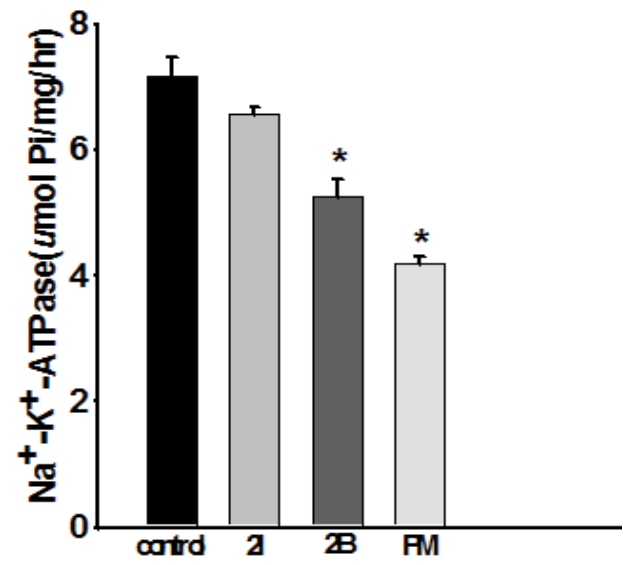

Figure 7: $\mathrm{Na}^{+}, \mathrm{K}^{+}-$ATPase activity in brain tissues. (A) Cerebral cortex; (B) Cerebellum; (C) Brain stem; and (D) Striatum $\left({ }^{*} \mathrm{p}<0.05\right)$.

\section{- Weight change}

Before injection, no significant differences in body weight were noted between groups. The mice showed decreased body weight after injection with 2C-I, 2C-B and PMMA (Figure 8). Untidy fur, back hump, and awkward stance were also noted after injection (Figure 9).

\section{Discussion}

In this study, we injected MA, 2C-I, 2C-B and PMMA in mice for 2 episodes of 4-day injections that were separated by 1 week of no injections to explore the psychoactive, addictive, and neurotoxic effects of these psychostimulants. We also evaluated neurochemical profiles in different parts of the brain of the mice to determine the underlying pathophysiology after drug injections. The behavioral tests showed impaired locomotor performance, rotarod balance performance, and water maze tests, increased CPP, and decreased time spent in the open field in the plus maze after injections. Neurochemical studies showed abnormal NOx, LPO, and $\mathrm{Na}^{+}, \mathrm{K}^{+}$-ATPase activities in brain tissues after injections. In the mice receiving injections, body weight decrease, and gross appearances like untidy fur, back hump, and awkward stance were also noted. Our results demonstrated that injection of $\mathrm{MA}, 2 \mathrm{C}$ I, 2C-B and PMMA in mice can impair motor activities, balance and memory performance, induce addiction and depression, and cause neurochemical abnormalities in brain tissues.

Like 3,4-methylenedioxyamphetamine (MDA), 3,4-methylenedioxymeth a m pheta mine (MDMA) 3,4-methylenedioxyethylamphetamine (MDEA), paramethoxyamphetamine (PMA) and PMMA are methoxy derivatives of 
Research Lin-Shiau Shoei-Yn
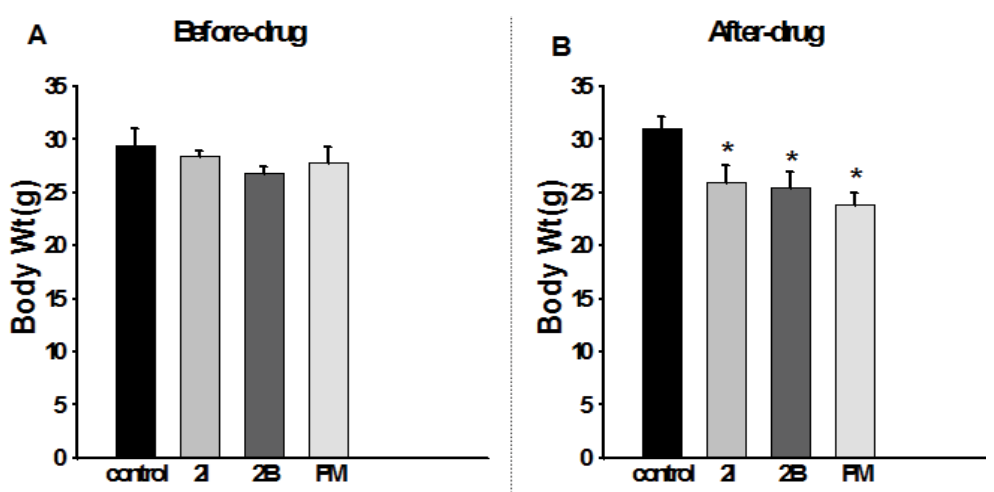

Figure 8: Body weight changes before $(A)$ and after $(B)$ injection $\left({ }^{*} p<0.05\right)$.
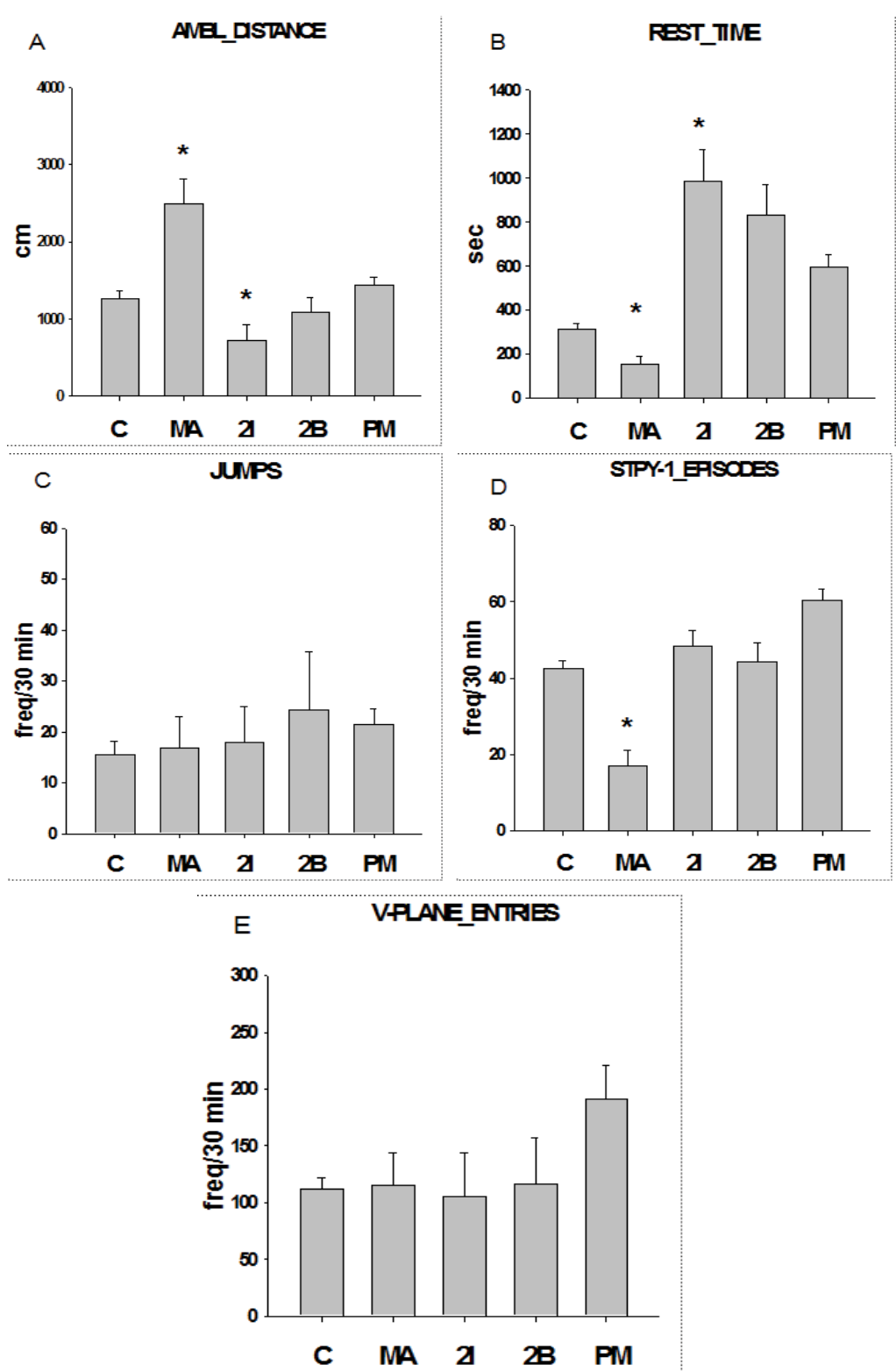

Figure 9: Locomotor activities of mice after intra-peritoneal injection of saline, MA, 2C-I, 2C-B and PMMA. (A) ambulation distance (B) rest time (C) jumps (D) stereotype-1 episodes, and (E) vertical plane entries $\left({ }^{*} p<0.05\right)$. 

Characterization of Psychoactive, Addictive, and Neurotoxic Effects of New Synthetic Amphetamine-like Research
2C-B, 2C-I and PMMA in Mice

phenylethylamines. All drugs exhibit hallucinogenic properties. However, paramethoxyl-derivatives have a slower onset of action and higher toxicities than their methylenedioxy counterparts $[9,15]$. In this study, it was surprising that the psychostimulating potency of PMMA was only one tenth that of MA; however, its toxicity was far more serious than that of MA. The psychostimulating effects of PMMA in locomotor tests were evident in the first phase, but decreased in the second phase. Even more, after repeated PMMA injections, the mice showed decreased weight, untidy fur, back humps, and awkward stances in appearance, and impaired memory performance in water maze tests. Depression was noted after repeated injection of PMMA despite an initial psychostimulating effect. Increased $\mathrm{NOx}$ and decreased $\mathrm{Na}^{+}, \mathrm{K}^{+}$-ATPase activity in the striatum, and increased $\mathrm{Na}^{+}, \mathrm{K}^{+}$-ATPase activity in the cerebellum were noted after PMMA injection. Chronic use of addictive drugs produces enduring neuroadaptations in the corticostriatal glutamatergic brain circuitry [16]. Therefore, the increased NOx and decreased $\mathrm{Na}^{+}, \mathrm{K}^{+}$-ATPase activity in the striatum after PMMA injection might have contributed to the late depressed--decreased locomotion and negative addictive effects.

Palenicek, et al. [17] reported that subcutaneous injection of 2C-B induced a biphasic effect on the locomotion of rats, with an initial inhibitory effect followed by an excitatory effect. Our results were consistent with theirs. In the first phase, the psychostimulating effects of $2 \mathrm{C}-\mathrm{B}$ were only one tenth those of MA. However, after halting injection for 1 week, repeated administration of 2C-B showed excessive psychostimulating effects. The CPP test demonstrated that $2 \mathrm{C}-\mathrm{B}$ is more addictive than MA. Besides, injection of 2C-B impaired rotarod performance and water maze tests, and increased NOx in the brain stem and striatum and LPO in the cerebral cortex and cerebellum, and decreased $\mathrm{Na}^{+}, \mathrm{K}^{+}-$ ATPase activity in the striatum. Of all the drugs we tested, $2 \mathrm{C}-\mathrm{B}$ was the most addictive and psychostimulating. Therefore, the potential problem of drug abuse with $2 \mathrm{C}-\mathrm{B}$ should be addressed.

The psychostimulating effects of 2C-I were not evident. However, after repeated injections of 2C-I, the mice became depressed, their locomotion decreased, and they stayed in the closed field longer. Increased LPO in the striatum and $\mathrm{Na}^{+}, \mathrm{K}^{+}$-ATPase activity in the brain stem were also noted. Therefore, repeated use of 2C-I induced significant neurochemical abnormalities, and its deleterious effects on locomotion and balance pose a serious health threat to users.

The drugs we used in this experiment were synthesized and provided by the FDA of Taiwan. Therefore, the quality and purity of the drugs we used were more predictable than that of drugs circulating on the street. The designer drugs used for recreation are usually not produced using strictly supervised procedures, so their quality and purity are not comparable to those in our experiments. Our results demonstrated that the psychostimulating effects of 2C-I, 2C$\mathrm{B}$, and PMMA were less than one tenth that of MA, and excessive neurotoxic effects were noted even in doses less than those achieving psychostimulation. Due to the lack of quality control, those who seek the psychostimulating effects of these drugs will frequently ingest much higher doses than that used in these experiments, and the neurotoxic effects will be exaggerated as the dose is increased. There have been deaths caused by the use of these designer drugs [9], and based on the results of our experiments; the fewer psychostimulating effects and lack of quality control with street drug use were the possible causes. Because of the severe neurotoxic effects noted after administration of these drugs, rigid regulation of production and usage, and a massive educational campaign on their potential neurotoxic effects are mandatory to control drug abuse.

\section{Conclusion}

We performed psychoactive, addictive, and neurotoxic tests after injecting mice with $2 \mathrm{C}$ I, 2C-B and PMMA. We found these designer drugs had fewer psychostimulating effects than MA, but the addictive and neurotoxic effects were comparable. In addition, neurochemical studies of different parts of the brain showed abnormal NOx, LPO, and $\mathrm{Na}^{+}, \mathrm{K}^{+}$-ATPase activities in brain tissues after injection. Due to lack of quality control, those who seek the psychostimulating effects of these drugs will frequently ingest much higher doses than that habitually used, and the neurotoxic effects will be exaggerated as the dose is increased. Based on our results, proper legal restriction of the use of these designer drugs and an educational campaign directed at the danger of their use are warranted to control drug abuse and counter the adverse effects of these drugs. 
Characterization of Psychoactive, Addictive, and Neurotoxic Effects of New Synthetic Amphetamine-like Research 2C-B, 2C-I and PMMA in Mice

\section{References}

1. Dean BV, Stellpflug SJ, Burnett AM, et al. $2 C$ or not $2 \mathrm{C}$ : phenethylamine designer drug review. J. Med. Toxicol 9(2), 172-178 (2013).

2. Haroz R, Greenberg MI. New drugs of abuse in North America. Clin. Lab. Med 26(1), 147-164 (2006).

3. Gold MS, Kobeissy FH, Wang KK, et al. Methamphetamine- and trauma-induced brain injuries: comparative cellular and molecular neurobiological substrates. Biol. Psychiatry 66(2), 118-127 (2009).

4. Kish SJ. Pharmacologic mechanisms of crystal meth. CMAJ 178(13), 1679-1682 (2008).

5. Panenka WJ, Procyshyn RM, Lecomte T, et al. Methamphetamine use: a comprehensive review of molecular, preclinical and clinical findings. Drug. Alcohol. Depend 129(3), 167-79 (2013).

6. Misawa F, Shimizu K, Fujii Y, et al. Is antipsychotic polypharmacy associated with metabolic syndrome even after adjustment for lifestyle effects?: a cross-sectional study. BMC. Psychiatry 11(1), 118 (2011).
7. Bosak A, LoVecchio F, Levine M. Recurrent seizures and serotonin syndrome following "2C-I" ingestion. J. Med. Toxicol 9(2), 196-198 (2013).

8. Huang HH, Bai YM. Persistent psychosis after ingestion of a single tablet of ' $2 \mathrm{C}-\mathrm{B}$ '. Prog. Neuropsychopharmacol. Biol. Psychiatry 35(1), 293-294 (2011).

9. Lin DL, Liu HC, Yin HL. Recent paramethoxymethamphetamine (PMMA) deaths in Taiwan. J. Anal. Toxicol 31(2), 109113 (2007).

10. Chuu JJ, Hsu CJ, Lin-Shiau SY. Abnormal auditory brainstem responses for mice treated with mercurial compounds: involvement of excessive nitric oxide. Toxicology 162(1), 11-22 (2001).

11. Huang CF, Liu SH, Lin-Shiau SY. Neurotoxicological effects of cinnabar (a Chinese mineral medicine, $\mathrm{HgS}$ ) in mice. Toxicol. Appl. Pharmacol 224(2), 192-201 (2007).

12. Itzhak Y, Martin JL. Cocaine-induced conditioned place preference in mice: induction, extinction and reinstatement by related psychostimulants.
Neuropsychopharmacology 26(1), 130-134 (2002).

13. Kim HJ, Soh Y, Jang JH, et al. Differential cell death induced by salsolinol with and without copper: possible role of reactive oxygen species. Mol. Pharmacol 60(3), 440-449 (2001).

14. Young YH, Chuu JJ, Liu SH, et al. Toxic effects of potassium bromate and thioglycolate on vestibuloocular reflex systems of Guinea pigs and humans. Toxicol. Appl. Pharmacol 177(2), 103-111 (2001).

15. Schifano F. A bitter pill. Overview of ecstasy (MDMA, MDA) related fatalities. Psychopharmacology (Berl) 173(3-4), 242-248 (2004).

16. Wydra K, Golembiowska K, Zaniewska M, et al. Accumbal and pallidal dopamine, glutamate and GABA overflow during cocaine self-administration and its extinction in rats. Addict. Biol 18(2), 307-324 (2013).

17. Palenicek T, Fujakova M, Brunovsky M, et al. Behavioral, neurochemical and pharmacoEEG profiles of the psychedelic drug 4-bromo2,5-dimethoxyphenethylamine (2C-B) in rats. Psychopharmacology (Berl) 225(1), 75-93 (2013). 